\title{
Making Space for Other Voices: Hands-On, Human-Centered Design Delivered Online
}

\author{
Kay C Dee (1) \\ Department of Biology and Biomedical Engineering, Rose-Hulman Institute of Technology, Terre Haute, IN 47803, USA
}

(Received 24 June 2020; accepted 20 July 2020; published online 11 August 2020)

\begin{abstract}
During the spring of 2020, due to the COVID-19 pandemic, it was necessary to rapidly translate a new humancentered design studio course for first-year biomedical engineering students from a face-to-face delivery mode to a remote delivery mode. In addition to disrupting plans for hands-on design prototyping experiences, stay-at-home orders associated with the pandemic disrupted plans for students to interact substantively and empathetically with potential users, which is the heart of human-centered design. The challenge was therefore to provide students without ready access to machine shops, 3D printing, or other people with some form of the educational experiences promised in the course syllabus.
\end{abstract}

Keywords-Design, Online education, Person-first language, Empathy.

\section{CHALLENGE STATEMENT}

During the spring of 2020, due to the COVID-19 pandemic, it was necessary to rapidly translate a new human-centered design studio course for first-year biomedical engineering students from a face-to-face delivery mode to a remote delivery mode. In addition to disrupting plans for hands-on design prototyping experiences, stay-at-home orders associated with the pandemic disrupted plans for students to interact substantively and empathetically with potential users, which is the heart of human-centered design. The challenge was therefore to provide students without ready access to machine shops, $3 \mathrm{D}$ printing, or other

Address correspondence to Kay C Dee, Department of Biology and Biomedical Engineering, Rose-Hulman Institute of Technology, Terre Haute, IN 47803, USA. Electronic mail: dee@rose-hulman.edu people, with some form of the educational experiences promised in the course syllabus:

"During this course, students will:

a. Follow processes inherent in

- Human-centered design.

b. Utilize fundamental STEM skills including aspects of

- Hands-on building,

- Failure analysis.

c. Develop productive, professional, healthy habits of mind related to

- Identifying and documenting user requirements,

- Prototyping,

- Active listening and empathy.

d. Produce functional products including

- Elevator pitches,

- Functional prototypes,

- Design posters."

\section{NOVEL INITIATIVE}

The first aspect of shifting to remote delivery was to ensure that the course site within the institutional learning management system (LMS; in this case, Moodle) followed Riggs and Linder's three-pronged approach to active learning in an online asynchronous environment. ${ }^{8}$ The three aspects of this approach are: 
(1) Creating an architecture of engagement (having an engagement policy, providing an orientation to the online environment; using a modular course structure); (2) Using a web-based tool outside of the LMS for more natural interactions (in this case, Microsoft Teams - school-provided and supported software) for informal virtual office hours, video conference checkins with individual design teams, and whole-class 'chat' questions and answers; (3) Using 'discussion boards' within the LMS as interactive student gallery or work spaces, instead of having students post an answer to a question and respond to two other posts.

The second aspect of shifting to remote delivery was to identify how to continue to support the framework used to describe the educational experiences in this course (processes, STEM skills, habits of mind, products), derived from Marshall and Herron's core elements to assess in 'maker' education. ${ }^{7}$ Retaining the 'maker' education elements was important since this course is part of an evolving effort ${ }^{3}$ to incorporate more constructivist-inspired activities and assessments ${ }^{9}$ across an undergraduate biomedical engineering curriculum. In agreement with the premise that "...the interaction among professionals of different backgrounds (engineering, medical, biology) particularly accentuates the need for [biomedical engineering] graduates to be adaptive in the application and extension of their content knowledge,", 4 we are collaboratively redesigning and coordinating courses to provide students more practice with the broad groupings of adaptive dispositions, metacognitive skills, and cognitive skills summarized nicely in Ref. 2. Two critical organizational adjustments allowed this course to continue to serve its intended position within the curriculum and enabled students to work within the intended framework even though the course was delivered remotely: 1. Creating new opportunities for students to 'practice' human interactions and empathy, and 2. Prioritizing the experience of learning from prototyping over the development of specific technical prototyping skills, and adapting materials and projects accordingly.

\section{'Practicing' Human Interactions and Empathy}

Empathetic interactions with users are the core of human-centered design. Since the instructor chose to define 'empathy' in accordance with Wiseman, ${ }^{11}$ students needed opportunities to consider the perspectives of others and then nonjudgmentally communicate how those others perceived the world, as well as how those others felt about their perceptions of the world. This was accomplished through a sequence of increasingly interactive and increasingly challenging tasks, coordinated with design iterations and techniques from
IDEO's Design Kit ${ }^{5}$ : Reading/listening to other (real) perspectives and reflecting on what was heard; reading fictitious user personas created by the instructor and constructing empathy maps for those personas; interviewing real people (close friends or family members) with whom they had already established relationships and practicing reading body language; remotely interviewing real people (Rose-Hulman Institute of Technology staff from administrative offices) with whom they had no previous relationship, attempting to read body language over video, and creating insight statements from those remote interviews.

The most broadly-applicable principle from these efforts is the following: delivering a course online gives us, as instructors, an opportunity to make space for other voices to be heard in our classes. We can curate resources from the wealth of the internet and include individuals who may not normally be well-heard in our field or in society. In this case, what might have originally been a face-to-face lecture on how to respectfully refer to individuals with disabilities became a fully online unit where the instructor's voice provided only concise introductions and summaries. Through short videos, blog posts, and websites, the voices of people with disabilities taught students about people-first language, identity-first language, the objectification of disability, and how to professionally refer to individuals with disabilities in design documentation.

A discussion forum within the LMS was then used to make space for student voices. Instead of being asked to discuss a question, ${ }^{8}$ students were asked to find an example of an article, news segment, image, etc. that did not follow the principles described in the unit. Students were then asked to post a link to the item they found, a brief description of what exactly violated the principles of the course unit, and a suggested rephrasing or refocusing that would improve the item. The responses to the online prompts were more thoughtful than typical in-classroom responses to discussion prompts. Students had time to think about and craft their contributions, and since each student was expected to post, all students 'spoke' to their peers and their instructor.

Instructors developing courses for the upcoming academic year are facing the possibility of once again needing to transition rapidly to remote delivery. An additional way to make space for other voices to be heard in our classes is to contact colleagues at other institutions and trade pre-recorded 'guest lectures,' trade expert commentary on student work or in video discussions, serve as remote design review panel members or competition judges, etc.

Given the continuing threat of COVID disruptions, and because referring respectfully to individuals with disabilities is a skill likely taught across many different 
courses in many different biomedical engineering programs, the Supplementary Resources (item 1) for this article will provide the hyperlinked text of this course unit so that it may be adapted and used by others.

\section{Adapting Expectations for Hands-On Prototypes}

The second most broadly-applicable principle from this initiative was to change the planned prototyping/ hands-on experiences to be accessible to students at home. Originally, multiple small design projects had been planned for this course, supplemented with hands-on shop training. The instructor revised the course based on the following personal philosophies/positions:

1. Any hands-on prototyping and 'making' experience would be better than no hands-on, 'making' experience. The instructor needed to work with the kinds of hands-on projects that are relatively easy to implement in a home environment (simple tools and supplies; online instruction available or feasible; low safety risks) without access to a shop.

2. These first-year students were experiencing unprecedented and disorienting levels of change in all aspects of their lives and education. The instructor needed to provide structure and constancy within the course whenever possible, to reduce anxiety and help students focus. One way to do this was to implement only one design project, addressing it more deeply than originally planned.

3. The course focus on empathy needed to be maintained as strongly as possible.

The instructor therefore implemented an overarching design challenge for this course: 'Design a hospital garment or garment system that provides patient dignity while allowing medical professionals to do their jobs.' This project was broad enough to provide a constant theme over multiple design tasks and deliverables, while also focused enough to allow students to make satisfying progress within one academic term. Prototypes could be created with home supplies and simple sewing tools/supplies. The specification of 'providing patient dignity' naturally requires empathetic design. Moreover, finding a way for students to interact with people outside of the 18-21 year-old demographic could provide new perspectives for students to consider, since people tend to have different hospital experiences at different ages and stages of life (e.g., emergency room visits, childbirth, extended stays or monitoring for chronic illnesses, etc.). Needing to move rapidly to remote learning, the instructor proceeded to develop a framework for students to "prac- tice' human interactions and empathy, as described in "Challenge Statement" section of this paper. This began with creating fictitious users to incorporate in the human-centered design and prototyping processes.

The instructor purchased Barbie $^{\mathrm{TM}}$ dolls online (spending roughly $\$ 165$ for 12 dolls - the maximum number of dolls obtainable within a self-imposed budget of roughly $\$ 150$ ) in a variety of body colors and shapes, and made additional alterations to the dolls to represent medical conditions and create more diverse body types within this group (Fig. 1). Images of the dolls (front, back, and side) placed in front of a ruled background were provided to students via email with fictitious user persona documentation for each doll (Fig. 2). Each team was assigned a specific persona/doll.

Students worked both individually and in teams of two (using Microsoft Teams for meetings) to follow the human-centered design process. Teams constructed empathy maps based on their assigned fictitious personas and completed design iterations based on those empathy maps. Each team then moved to interacting with real people, holding two video conference interviews (using Microsoft Teams) with individual RoseHulman staff members, utilizing 'conversation starter' on-paper garment designs. These staff members had responded to broad emails from the instructor seeking people willing to be interviewed by either one or two student teams. The instructor targeted staff (e.g., Business Office staff, Alumni Affairs staff, Technicians), believing that a) most faculty were likely overwhelmed with their own remote courses, and b) the first-year students in the course would be unlikely to have already developed relationships with these staff members. The staff interviews therefore provided students with new perspectives and let them practice interacting professionally with unfamiliar individuals.

Teams consolidated feedback from the staff interviews with ideas from the empathy maps of their assigned user persona. After on-paper iterations and selecting one design to continue developing, student teams drafted to-scale patterns for their designs, intended to fit their assigned persona/doll. Each student was then asked to independently create a prototype out of paper using the jointly-created pattern as a guide, and afterward to meet with their teammate, compare the resultant prototypes, and revise the design and pattern as a team for consistent interpretation and better function. After the paper prototyping experiences, students were asked to individually create fabric prototypes to fit their assigned persona/doll using supplies that they had received in the mail (details below in "Materials and Shipping Logistics" section). Each team then met again to discuss whose fabric prototype best represented the features of their design. 

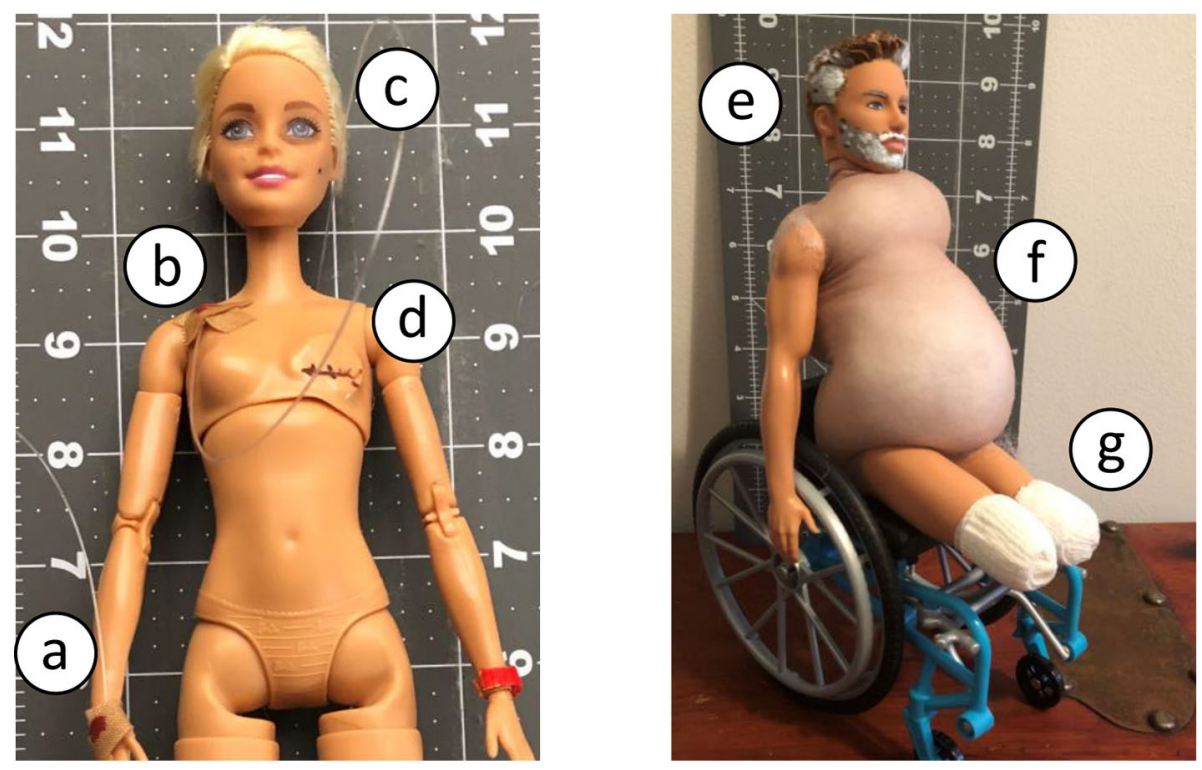

FIGURE 1. Example doll alterations. Dolls were altered to represent a range of body types, plausible reasons for hospital stays, and possible challenges for hospital garment design: (a) a representation of an intravenous cannula placed on the back of the hand, with monofilament representing a catheter; (b) a representation of a chemotherapy port, with monofilament representing a catheter; (c) shorn hair to represent hair loss from chemotherapy; (d) application of a heat gun and pressure, combined with a painted scar, represent some physical effects of a mastectomy; (e) paint applied to create the perception of age due to gray hair and beard; (f) creation of a larger body profile by applying a covering of polyester fiber fill contained in a piece of nylon stocking; (g) below-knee double amputation.

All students sent their individual fabric prototypes to the instructor for assessment (details in "Materials and Shipping Logistics" section) using the rubric below.

The prototype:

- Reasonably fits the assigned user persona doll model. Can the prototype be put on the assigned doll model? Once on, does it fall off, gap open, or tear?

- Illustrates the real-world functionality of the design. Can someone look at this prototype and its supporting documentation and easily agree that the feasibility criteria are met by the prototype?

- Provides an approximation of the actual aesthetics of the real-world product. Can someone look at this prototype and easily identify it as what is described in your supporting documentation?

Students received a completed rubric/grade in the LMS, and a picture (via email) of their assigned doll wearing their fabric prototype. If a student's prototype did not fit the doll, they received a picture of the instructor's best attempt to place the prototype on the doll (e.g., the images in Fig. 3 were provided to a student).

Like the shift to asynchronous online instruction overall, this asynchronous hands-on activity made space in the course for voices beyond the instructor.
First, the experiences and perspectives shared by the staff members were important parts of the humancentered design process. Second, two students in the course turned out to be accomplished sewists, and held online tutorials and office hours to assist their peers with the fabric prototypes. Third, multiple students told the instructor that their mother, father, or grandmother helped them practice sewing at home, and were pleased to contribute to their education.

\section{Materials and Shipping Logistics}

Students submitted their postal mailing addresses to the instructor via a questionnaire within the LMS, and with the help of the school's mailroom personnel, the instructor used the US Postal Service (carrier selected by mailroom personnel for price) to mail each student a 'fat quarter' (a pre-cut, 18 inch $\times 22$ inch, onequarter yard) of cotton fabric, a spool of coordinating thread, a sewing needle sheathed in corrugated cardboard (spending roughly $\$ 200$ on sewing supplies for 34 students), and a pre-paid, self-addressed Federal Express envelope (carrier selected by mailroom personnel for shipping speed). Shipping the supplies to students cost $\$ 110$; shipping the completed fabric prototypes to the instructor cost $\$ 200$. There were no institutional restrictions on mailing items to or receiving items from students, beyond contact-free 

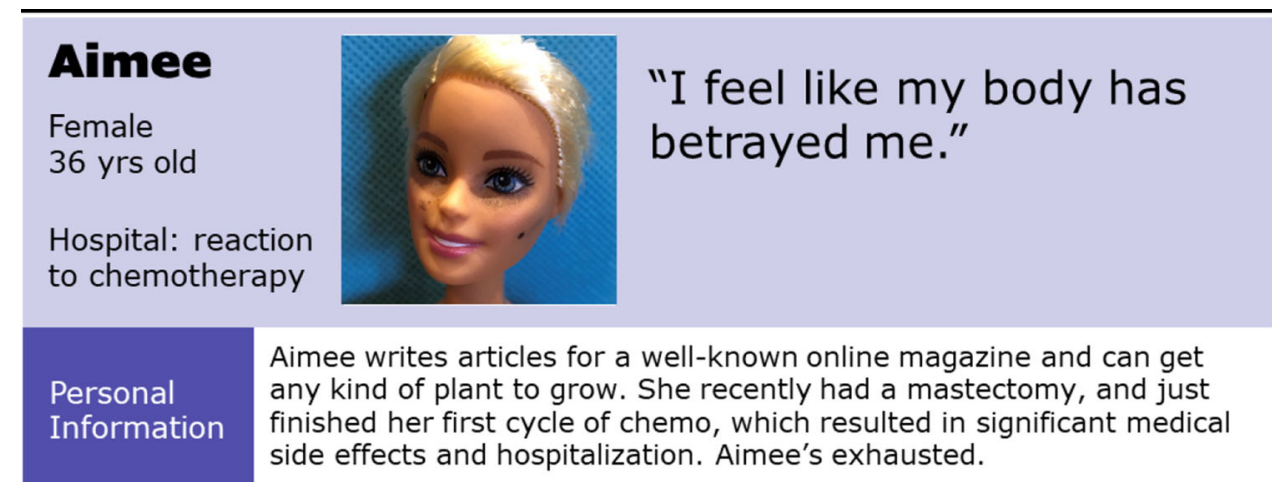

Aimee writes articles for a well-known online magazine and can get any kind of plant to grow. She recently had a mastectomy, and just finished her first cycle of chemo, which resulted in significant medical side effects and hospitalization. Aimee's exhausted.

\begin{tabular}{|c|c|c|}
\hline Health goals & Health-related values & Health fears \\
\hline $\begin{array}{l}\text { - } \text { Stopping the } \\
\text { nausea. } \\
\text { - Regaining mental } \\
\text { clarity instead of }\end{array}$ & $\begin{array}{l}\text { - Grit and } \\
\text { determination. } \\
\text { - Focusing on what } \\
\text { can be controlled. }\end{array}$ & $\begin{array}{l}\text { - That even with all } \\
\text { she is going } \\
\text { through, the cancer } \\
\text { could come back. }\end{array}$ \\
\hline
\end{tabular}
brain.'

- Eliminating the cancer.

FIGURE 2. Example fictitious user persona. Dolls were altered to personify fictitious user personas created by the instructor. Personas provided a small amount of 'personal information' as well as 'health-related goals, values, and fears.' Students used this information to create empathy maps for their assigned persona as a human-centered design practice.
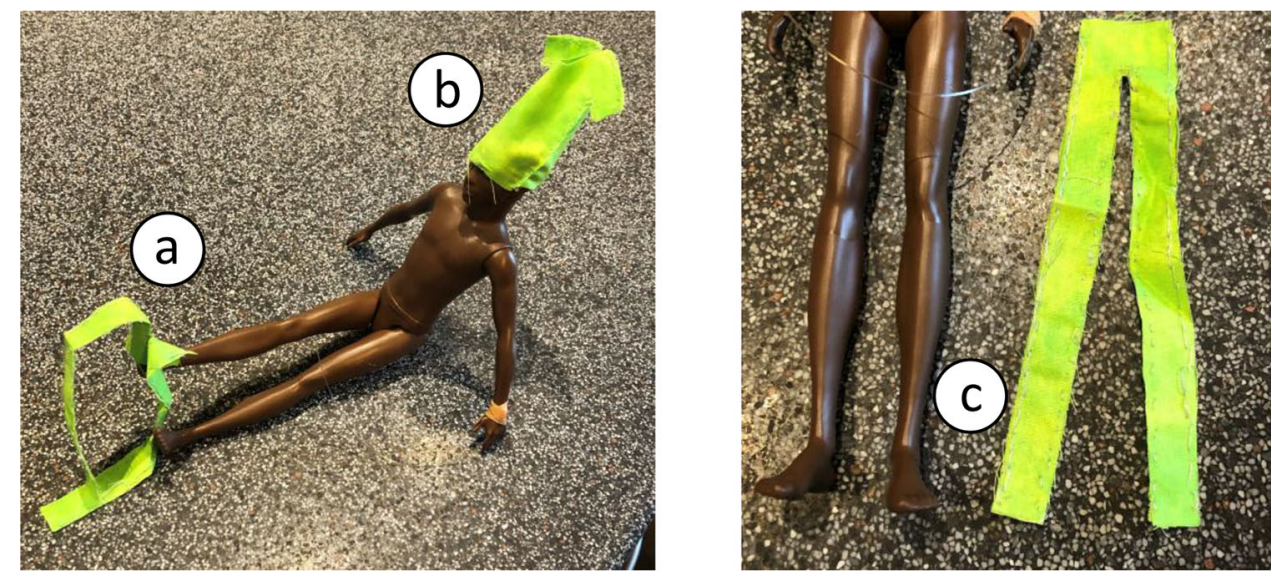

FIGURE 3. Extreme example of prototype failure. One of the most unsuccessful fabric prototypes is shown here: (a) the pants submitted do not fit over the doll's foot; (b) the shirt submitted cannot fit over the doll's head; (c) a comparison of the long thin legs of the doll and the long thin legs of the submitted pants suggest that the student considered only the front view of the doll when constructing the prototype, failing to consider either a seam allowance or the three-dimensional thickness of the doll legs.

interactions between the instructor and mailroom personnel (e.g., the instructor left the box of completed supply packages outside the facilities building after speaking with mailroom personnel on the phone; mailroom personnel retrieved and processed the box of packages after the instructor left). Overall, a total of \$20 per student was spent on dolls, supplies, and shipping; $\$ 9$ of this per-student cost was due to shipping.

\section{REFLECTION}

From the student perspective: Comments on the end-of-term student evaluations (see the Supplementary Resources, item 2, for the specific questions asked) indicated that the course was well-received overall. Instructor responsiveness to questions, strong social presence in the online environment, and reaching out to check on students were cited as positive aspects of 
the course. Students also expressed gratitude for the step-by-step nature and consistent format of assignments ("what was expected of us was spelled out very clearly"). Student comments focused on instructor practices and the online environment, instead of the experiences promised in the course syllabus. The only substantive suggestions for changing the course were to mail each team their assigned doll in addition to the prototyping supplies, and to reduce the number of design iterations required.

From the instructor perspective: The general educational experiences promised in the course syllabus framework were delivered, which was the main instructor goal. Students spent more time following processes inherent in human-centered design than originally planned for the course. Students did utilize fundamental STEM skills, but in ways different from those originally envisioned for this course, and to a lesser degree than originally planned. Students practiced habits of mind related to identifying and documenting user requirements, prototyping, and active listening and empathy, as anticipated. Finally, students produced the anticipated functional products including elevator pitches, prototypes, and design posters. The instructor was also pleased with the cognitive and social presence of the students in the online environment; students were working together and regularly communicating with each other and the instructor.

Although many of the fabric prototypes were fine, some prototypes were disappointing. This was not a function of sewing skill. Rather, some students appeared to have a hard time using the measurements present in the two-dimensional pictures of the dolls to produce three-dimensional garments that fit the dolls (an extreme example of this is shown in Fig. 3), even though all the students had already passed a graphical communication course which emphasizes two- and three-dimensional visualization and engineering drawing. This is not a surprising outcome in general; educators have struggled for years to improve the visualization skills of students. ${ }^{6,10}$ In this specific case, however, students were attempting to create prototypes of real-world objects (pants; shirts) with which they are extremely familiar and to which they had ample access for exploration and comparison. The instructor plans to emphasize these facts when offering this course remotely again during the spring of 2021 . Other changes under consideration include purchasing and mailing extra fabric to each student in their supply envelope to provide for additional fabric prototype iterations. The instructor is also considering, as suggested by a student, purchasing one doll for each team and mailing each team their assigned doll (with extra pre-paid envelopes addressed to each team member). This would allow each student to try their individual fabric prototype on their assigned doll, and should improve the quality of the final fabric prototypes.

Assessment of the effectiveness of this online humancentered design course will occur in two parts. First, the instructor collected student self-assessments of empathetic traits using the Basic Empathy Scale from Carré et al. ${ }^{1}$ both before and after the course. The instructor intends to analyze whether student responses on the Basic Empathy Scale shifted after taking the course described in this paper, but analysis of these data is not yet complete. Second, during their first-term, second-year biomedical engineering design studio, the students who were in the course described in this paper will be tasked with outlining a human-centered design approach to address a challenge for an individual with a disability. Review of that work will allow instructors to see which aspects of the human-centered design process, empathetic perspective-taking, and person-first language were retained by the students.

\section{ELECTRONIC SUPPLEMENTARY MATERIAL}

The online version of this article (https://doi.org/10. 1007/s43683-020-00003-2) contains supplementary material, which is available to authorized users.

\section{ACKNOWLEDGMENTS}

Dr. Daniel Tetteh-Richter, Senior Instructional Designer at Rose-Hulman Institute of Technology, created and maintains the table of 'Appropriate Terminology' included in the Supplemental Resources for this article.

\section{AUTHOR CONTRIBUTIONS}

This is a single-author contribution.

\section{DATA AVAILABILITY}

The author will share critical material from this article as Electronic Supplementary Materials.

None.

\section{CONFLICT OF INTEREST}

\section{REFERENCES}

${ }^{1}$ Carré A, Stefaniak S, D'Ambrosio F, Bensalah L, BescheRichard C. The basic empathy scale in adults (BES-A): 
factor structure of a revised form. Psychol Assess 2013;25(3):679-91.

${ }^{2}$ De Arment ST, Reed E, Wetzel AP. Promoting adaptive expertise: A conceptual framework for special educator preparation. Teach Educ Special Educ 2013;36:217-30.

${ }^{3}$ Dee KC, Brackin P, Watt A, Chiu A, Livesay G, McCormack JP, Rogge RD, House RA. An engineering design-oriented first year biomedical engineering curriculum. In: Proceedings of the 2018 American Society for Engineering Education Annual Conference \& Exposition. American Society for Engineering Education, 2018. http s://peer.asee.org/29779. Accessed 10 August 2020.

${ }^{4}$ Fisher FT, Peterson PL. A tool to measure adaptive expertise in biomedical engineering students. In: Proceedings of the 2001 American Society for Engineering Education Annual Conference \& Exposition. American Society for Engineering Education, 2001. https://www.researchga te.net/profile/Frank_Fisher/publication/238430041_A_To ol to Measure Adaptive Expertise in Biomedical_Engin eering_Students/links/552fd9400cf27acb0de7f5c2.pdf. Accessed 15 July 2020.

${ }^{5}$ IDEO. Methods. In: Design Kit. IDEO.org https://www.de signkit.org/methods. Accessed 24 Jun 2020.

${ }^{6}$ Katsuloudis P, Jones K. Using computer-aided design software and 3D printers to improve spatial visualization. Technol. Eng. Teac. 2015;74:14-20.
${ }^{7}$ Marshall JA, Harron JR. Making learners: a framework for evaluating making in STEM education. Interdiscip. J. Probl Learn. 2018. https://docs.lib.purdue.edu/ijpbl/vol12/ iss $2 / 3 /$. Accessed 15 July 2020.

${ }^{8}$ Riggs SA, Linder KE. Actively engaging students in asynchronous online classes. IDEA Paper \#64, 2016. https:// www.ideaedu.org/Portals/0/Uploads/Documents/IDEA \% 20Papers/IDEA \%20Papers/PaperIDEA_64.pdf. Accessed 24 Jun 2020.

${ }^{9}$ Schwartz DL, Lindgren R, Lewis S. Constructivism in an age of non-constructivist assessments. In: Tobias S, Duff TM, editors. Constructivist instruction: success or failure? New York: Routledge/Taylor \& Francis Group; 2009. pp. 34-61.

${ }^{10}$ Sorby SA, Baartmans BJ. A course for the development of 3D spatial visualization skills. Eng. Des. Graph. J. 1996;60:13-20.

${ }^{11}$ Wiseman T. A concept analysis of empathy. J. Adv. Nurs. 1996;23:1162-7.

Publisher's Note Springer Nature remains neutral with regard to jurisdictional claims in published maps and institutional affiliations. 